\title{
Benchmarking study between capacitive and electronic load technic to track I-V and P-V of a solar panel
}

\author{
Abdellah Asbayou, Amine Aamoume, Mustapha Elyaqouti, Ahmed Ihlal, Lahoussine Bouhouch \\ Laboratory of Materials and Renewable Energies, University Ibn Zohn, Agadir, Morocco
}

\begin{tabular}{l}
\hline \hline Article Info \\
\hline Article history: \\
Received Mar 14, 2021 \\
Revised Jul 15, 2021 \\
Accepted Aug 10, 2021 \\
\hline
\end{tabular}

Keywords:

Arduino board

Capacitive load

Electronic load

I-V track system

Solar panel

\begin{abstract}
To detect defects of solar panel and understand the effect of external parameters such as fluctuations in illumination, temperature, and the effect of a type of dust on a photovoltaic (PV) panel, it is essential to plot the $\mathrm{Ipv}=\mathrm{f}(\mathrm{Vpv})$ characteristic of the PV panel, and the simplest way to plot this $\mathrm{I}-\mathrm{V}$ characteristic is to use a variable resistor. This paper presents a study of comparison and combination between two methods: capacitive and electronic loading to track I-V characteristic. The comparison was performed in terms of accuracy, response time and instrumentation cost used in each circuit, under standard temperature and illumination conditions by using polycrystalline solar panel type SX330J and monocrystalline solar panels type ET-M53630. The whole system is based on simple components, less expensive and especially widely used in laboratories. The results will be between the datasheet of the manufacturer with the experimental data, refinements and improvements concerning the number of points and the trace time have been made by combining these two methods.
\end{abstract}

This is an open access article under the CC BY-SA license.

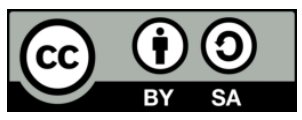

\section{Corresponding Author:}

Abdellah Asbayou

Laboratory of Materials and Renewable Energies, Faculty of science Agadir, Ibn Zohr University

BP 8106, 80000 Agadir, Morocco

Email: abdellah.asbayou@edu.uiz.ac.ma

\section{INTRODUCTION}

The production of photovoltaic technology has grown exponentially worldwide in recent years. The most crucial component of a solar system is the photovoltaic module, which can sometimes be relatively difficult to diagnose. Defects and the effect of external parameters such as fluctuations in illumination, temperature, and the effect of dust as partial shading [1], on the modules are generally not visible to the naked eye and their causes must also be found by indirect and special methods [2].

One of the most important parameters for the diagnosis, monitoring, or characterization of PV systems is the curve $I p v=f(V p v)$ (or $I-V$ ) of the photovoltaic (PV) module. This $I-V$ characteristic provides important information about the performance of the PV modules, such as the open-circuit voltage Voc, the short-circuit current $I_{S C}$, the rated maximum power $P_{M P P}$, the current Imp, and voltage Vmp of the maximum power point and the module efficiency. These parameters are extremely important for the operation, testing, calibration, commissioning, design, maintenance, and control of PV systems [3].

There are many methods to trace the $I-V$ characteristic of a PV module under different operating conditions [4]. The easiest and method is to use a variable resistor to change the values of current and voltage, thus the $I-V$ characteristic can be extracted. Such a method has been used in some previous research works [5], [6]. Another way to plot the $I-V$ curve of a PV generator is to use capacitive charges as the capacitor charge increases, the current drops, and the voltage increases. When the charge is completed, the current supplied by the PV generator becomes zero and the open circuit condition is reached. Some research 
in [7]-[9] have used capacitors as an automatic variable charge to vary the voltage $V p v$ and current Ipv during the capacitor charging operation, which has allowed them to obtain the $I$ - $V$ characteristic of the PV array.

Chen et al. [10] have designed a device based on an electronically variable load using the APL501J MOSFET transistor, covering the full range of the $I-V$ characteristic. The electronic charging method uses a transistor (usually a MOSFET) as a load. The resistance between drain and source and the flow of the current supplied by the PV generator are modulated by the gate-source voltage. When this method is used to plot the $I-V$ curve of the PV generator, the MOSFET must operate in its three modes (off, active and ohmic) to obtain the $I-V$ characteristic of the PV array in a very short time

This article proposes a comparison and combination study between two methods to track the $I-V$ output of a solar panel; capacitive and electronic loading, and for this reason, this paper is divided into 5 sections: The first one gives the introduction concerning the methods used to arrive at the $I$ - $V$ characteristic of a PV panel. Then in section 2, we give a brief mathematical description of the two methods used. Then, in section 3, we give details on the measurement bench, and section 4 summarizes and discusses the results obtained. We will end this article with a conclusion of this work.

\section{SOLAR CELL MATHEMATICAL MODEL}

There are many solar cell models that predict the electrical behavior of a solar panel. The singlediode model of a solar cell is the most frequently used model to simulate photovoltaic power generation [11]. For a solar cell whose electrical modeling is given in Figure 1, The electrical current Ipv is related to the voltage Vpv by (7) according to the 1 diode model as shown in Figure 1.

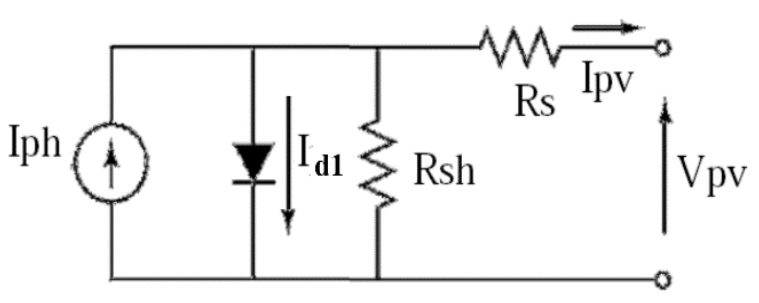

Figure 1. Equivalent circuit of a PV cell with 1 diode

The photo-current Iph depends linearly on solar radiation G, but is also influenced by temperature, according to the following relation [12]:

$$
I_{p h}=\left(I_{p h, r e f}+\alpha_{0} \cdot \Delta T\right) \frac{G}{G_{r e f}}
$$

In the standard test conditions $(S T C)\left(\right.$ Gref $=1000 \mathrm{~W} / \mathrm{m}^{2}$, Tref $\left.=298 \mathrm{~K}\right)$, the expression of $I p h$, ref is given by (2):

$$
I_{p h, r e f}=\left(1+\frac{R_{S}}{R_{S h}}\right) I_{s c, r e f}
$$

Therefore:

$$
I_{p h}=\left(\left(1+\frac{R_{s}}{R_{s h}}\right) I_{s c, r e f}+\alpha_{0} \Delta T\right) \frac{G}{G_{r e f}}
$$

By application of the meshes law, the $I_{s h}$ current in the shunt resistor $\mathrm{R}_{\mathrm{sh}}$ is expressed by (4):

$$
I_{s h}=\frac{V_{p v}+R_{S} I_{p v}}{R_{S h}}
$$

The diode current $I_{d i}$ is given by (5),

$$
I_{d 1}=I_{01}\left[\exp \left(\frac{V_{p v}+R_{S} I_{p v}}{n_{1} V_{t h}}\right)-1\right]
$$


with (6),

$$
I_{01}=\frac{I_{S c, r e f}+a_{0} \Delta T}{\exp \left(\frac{V_{o c, r e f}+\beta_{0} \Delta T}{V_{t h}}\right)-1}
$$

and $V_{t h}=\frac{k T}{q}$ is the thermal voltage of the module, $\alpha_{0}$ temperature correction coefficient for current $\left({ }^{\circ} \mathrm{C}^{-1}\right)$, $\beta_{0}$ temperature correction coefficient for voltage $\left({ }^{\circ} \mathrm{C}^{-1}\right), I_{0}$ reverse saturation current (A), $n_{1}$ first diode ideality factor, and $R_{S}$ series resistance $(\Omega)$. So, the current supplied by the solar cell in 1 diode model is given by the following relation [13].

$$
I_{p v}=I_{p h}-I_{01}\left[\exp \left(\frac{V_{p v}+R_{S} I_{p v}}{n_{1} V_{t h}}\right)-1\right]-\frac{V_{p v}+R_{S} I_{p v}}{R_{S h}}
$$

Many approaches for determining the performance of solar panels can be adopted based on the data sheet of the parameters specified by the manufacturer or measured. The performance of a solar panel is normally evaluated under standard test conditions (STC), where an average solar spectrum at AM 1.5 is used, irradiance is normalized to $1000 \mathrm{~W} / \mathrm{m}^{2}$, and the cell temperature is set at $25^{\circ} \mathrm{C}$ [14]. The panels used in this work are polycrystalline type SX 330J, and monocrystalline type ET-M53630, whose electrical characteristics are summarized in Table 1.

Table 1. Electrical characteristics of the PV module SX330 and ET-M53630 at STC [15]

\begin{tabular}{ccc}
\hline Symbol & Value (SX330 panel) & Value (ET-M53630 panel) \\
\hline$P_{\max }$ & $30 \mathrm{~W}$ & $30 \mathrm{~W}$ \\
$V_{m p}$ & $16.8 \mathrm{~V}$ & $17.72 \mathrm{~V}$ \\
$I_{m p}$ & $1.78 \mathrm{~A}$ & $1.69 \mathrm{~A}$ \\
-- & $27 \mathrm{~W}$ & $28.5 \mathrm{~W}$ \\
$I_{s c}$ & $1.94 \mathrm{~A}$ & $1.80 \mathrm{~A}$ \\
$V_{o c}$ & $21.0 \mathrm{~V}$ & $21.52 \mathrm{~V}$ \\
\hline
\end{tabular}

\section{MATERIALS AND METHODS}

The proposed measurement bench for the real-time characterization of the PV panel, is realized by using an Arduino UNO board, as acquisition, and data transfer unit of $I_{P V}$ and $V p v$ values to a personal computer via PLX-DAQ tool as shown in Figure 2. PLX-DAQ from Parallax is a complementary data acquisition tool for Microsoft Excel, which acquires up to 26 channels of data from any microcontroller and allows simple analysis of spreadsheets of data collected in the field [16]. The values of the PV array's current intensity I $p v$ and voltage $V p v$ are measured using two Arduino-compatible voltage sensors, one measuring the voltage and the other used as a current sensor. The PV array temperature is measured using a thermocouple, while the irradiance is evaluated using the FI 109SM solarimeter [17].

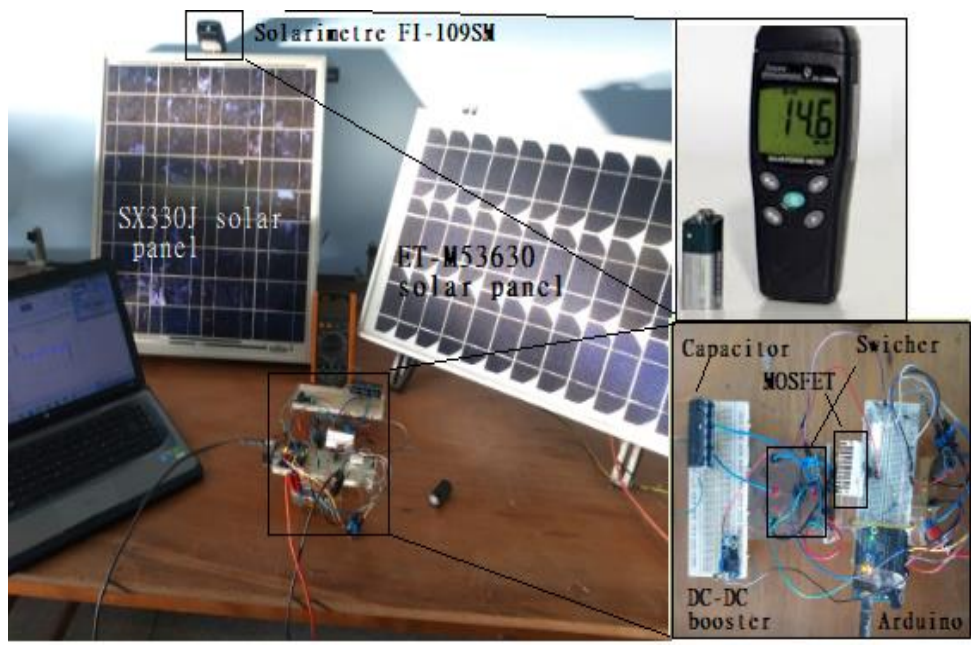

Figure 2. Prototype version used for the developed experimental campaign 


\subsection{Instrument cost}

In this paper, the objective is to realize a low-cost solution of simple instrumentation to provide $I$ - $V$ $\& P-V$ characteristics, to analyze the influence of real operating conditions, such as temperature, illumination, dust shadowing effect, and real-time observation of PV module performance, based on simple components, and less expensive. Table 2 present the partial and total cost (USD) of the electronic components used in each technique, capacitive or electronic load.

Table 2. Partial costs and total cost of the materials and components associated to the project

\begin{tabular}{cccc}
\hline \multicolumn{2}{c}{ System components } & $\approx$ Partial cost & Total cost \\
\hline RC capacitive load & Resistor & 1 USD & 25.8 USD \\
& Capacitor & 2 USD & \\
& Voltage sensor & 8.8 USD & \\
& Arduino UNO & 15 USD & \\
& Resistor & 1 USD & \multirow{6}{*}{ Electronic load (MOSFET) } \\
& Resistor & 2 USD & 33.8 USD \\
& Capacitor & 4 USD & \\
& Voltage sensor & 8.8 USD & \\
& Arduino UNO & 15 USD & \\
& DC/DC booster & 4 USD & \\
& MOSFET & 1 USD & \\
\hline
\end{tabular}

\subsection{Instrument calibration}

The developed instrument was subjected to a calibration process based on a DGM-360 digital multimeter. This calibration was performed by acquiring discrete values of the voltage and current applied by a solar panel under well-defined illumination and temperature conditions [18]. This instrument has a voltage resolution of $0.01 \mathrm{~V}$ in the range of $60-4 \mathrm{~V}$, and a current resolution of $0.001 \mathrm{~A}$ in the measuring range of $6 \mathrm{~A}$. The uncertainty given by the manufacturer is $0.02 \%$. The process has been carried out over the entire operating range established for each measuring sensor, then, the calibration equations were obtained using a linear fit.

\subsection{Experimental I-V curve tracer topology with capacitive load}

The PV module I-V curve plotter proposed in this section is based on a fast and automatic variation of the capacitor charge, as shown in Figure 3, with $\mathrm{R}=4 \Omega, \mathrm{C}=4.7 \mathrm{mF}$. The maximum voltage value of the capacitor must be $20 \%$ higher than the Voc of the solar module for safety reasons. The capacitance value C must therefore be calculated for each scenario [7]. After thorough analysis and experimental work, it is recommended to select the capacitance value $\mathrm{C}$ using expression (8):

$$
\mathrm{C} \approx 0.55 \mathrm{t}\left(\frac{I_{S c}}{V o c}\right)
$$

where $\mathrm{t}$ is the capacitor charge time, which must be greater than $20 \mathrm{~ms}$ for Isc and Voc conditions close to standard test conditions (STC).

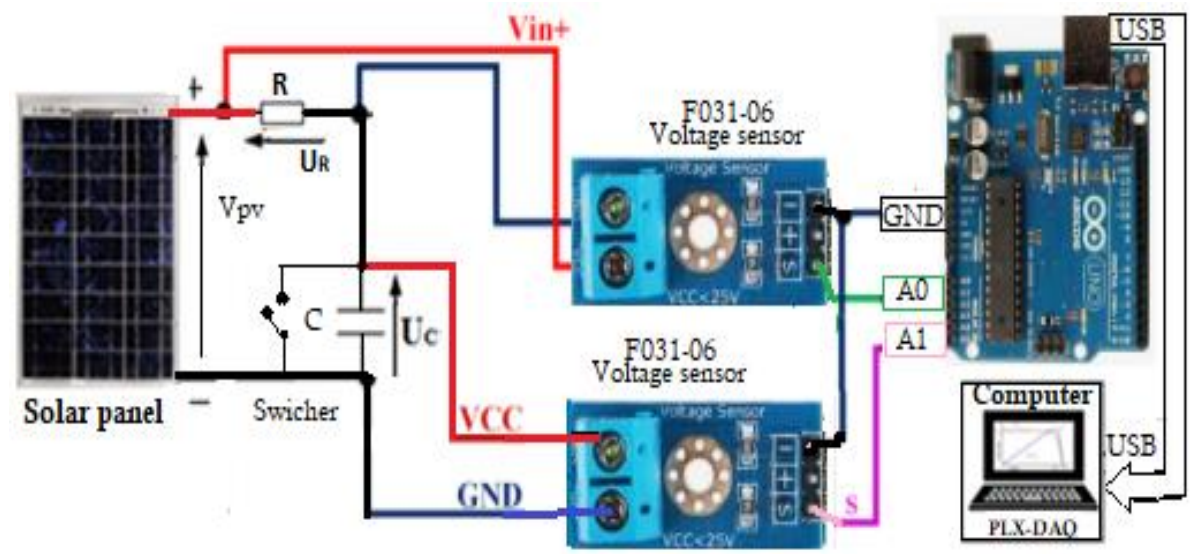

Figure 3. Synoptic diagram of PV characterization carried out with "RC" circuit method 
In this case, theoretically according to the mesh-law applied to the circuit in Figure 3, we have:

$$
V_{p v}=U_{c}(t)+U_{R}(t)
$$

or:

$$
V_{p v}=U_{c}(t)+R C \frac{d U c(t)}{d t}
$$

The solution of the differential equation appearing in (10) is given by (11):

$$
U_{c}(t)=V_{o c} \cdot\left(1-e^{-\frac{t}{R C}}\right)
$$

where: $V_{O C}$ Solar cell open-circuit voltage $(\mathrm{V})$, so:

$$
V_{p v}=V_{o c} \cdot\left(1-e^{-\frac{t}{R C}}\right)+U_{R}(t)
$$

and the intensity of the current $I_{p v}(t)$ :

$$
I_{p v}=C \frac{d U_{c}(t)}{d t}
$$

Finally,

$$
I_{p v}=\left(V_{o c} / R\right) \mathrm{e}^{\left(\frac{-t}{R C}\right)}
$$

\subsection{Experimental I-V curve tracer topology with electronic load}

Figure 4 shows the block diagram of the experimental $I-V$ curve plotter for PV modules using the electronic charging method based on an IRF740 MOSFET transistor. The MOSFET is an electrical component that functions as an electronically controlled load, which changes the operating point of an $I-V$ of PV generator [19]. When a $V_{G S}$ control voltage is applied to its gate, it generates a fast and variable PV output current from 0 to Isc (A) and a variable output voltage from Voc to 0 (V). The Arduino board generates a continuous signal through pin $V c c=5 \mathrm{~V}$, then amplified by a DC/DC booster XL6009E1, then this signal is injected into an $\mathrm{RC}$ filter $(\mathrm{R}=440 \Omega, \mathrm{C}=4.7 \mathrm{mF})$, to vary the control voltage VGS of the MOSFET in a progressive way, which also requires the RDS resistor to evolve progressively [20].

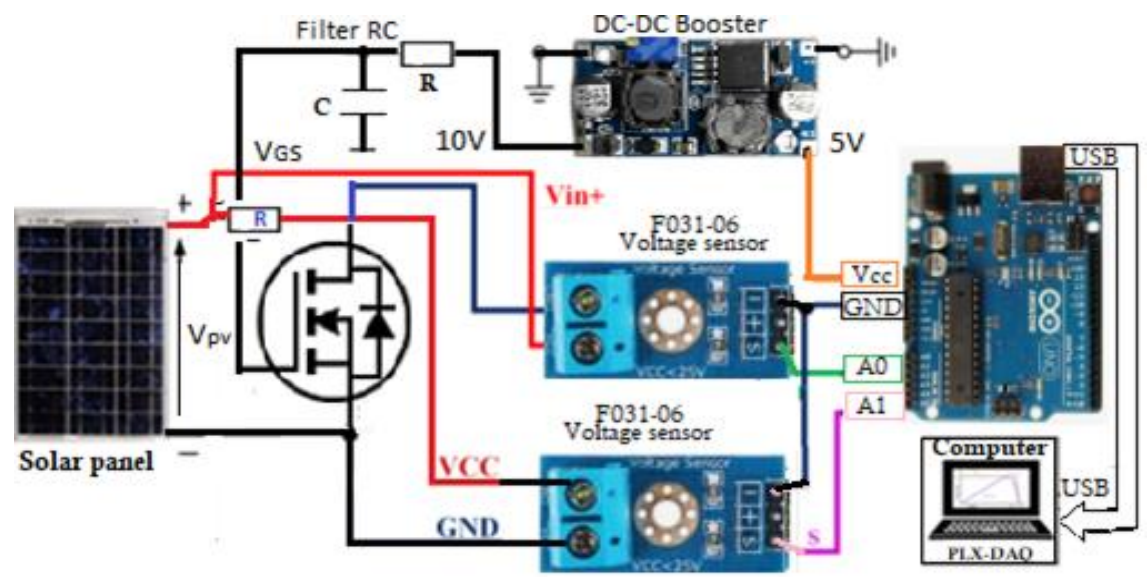

Figure 4. Synoptic diagram of electronic load technic

The three operating modes of the MOSFET that describe the relationship between $I_{D}$ as a function of $\mathrm{V}_{\mathrm{GS}}$ and $\mathrm{V}_{\mathrm{DS}}$ are [21]. 
Cutoff mode if:

$$
\mathrm{V}_{\mathrm{GS}}<\mathrm{V}_{\text {th }} \text { alors } \mathrm{I}_{\mathrm{D}}=0 \mathrm{~A}
$$

Ohmic mode if:

$$
V_{G S}-V t h>0 \& V_{G S}-V t h>V_{D S} \text { alors }: I_{D}=K\left[2\left(V_{G S}-V t h\right) V_{D S}-V_{D S}^{2}\right]
$$

Saturation mode if:

$$
V_{G S}-V t h>0 \& V_{G S}-V t h<V_{D S} \text { alors }: I_{D}=K\left(V_{G S}-V t h\right)^{2}
$$

where $\mathrm{K}$ is the device constant and $\mathrm{V}_{\mathrm{th}}$ is the transistor control threshold voltage. By changing the $\mathrm{V}_{\mathrm{GS}}$ value within an appropriate range, measurement points can scan between $I_{S C}$ and $V_{O C}$, with:

$$
I_{D}=I p v
$$

\section{RESULTS AND DISCUSSION}

\subsection{Time response comparison at $25{ }^{\circ} \mathrm{C}$ and $\mathbf{G}=1000 \mathrm{~W} / \mathrm{m}^{2}$}

The Figures 5(a)-(b) and 6(a)-(b) show the variation of $I p v$ and $V p v$ as a function with time, Figure 6(a) for electronic technic and Figure 6(b) capacitive technic, in the case of variation of R resistor and $\mathrm{C}$ capacitor, to evaluate the response time by the two previous technics: Capacitive and electronic load. From Figures 5 and 6 we can observe that if the value of $\mathrm{R}$ and $\mathrm{C}$ increases, the time required to plot the $I-V$ or $P-V$ characteristic increases, using both techniques. But the technique using MOSFET is faster than the capacitive one in the response time.

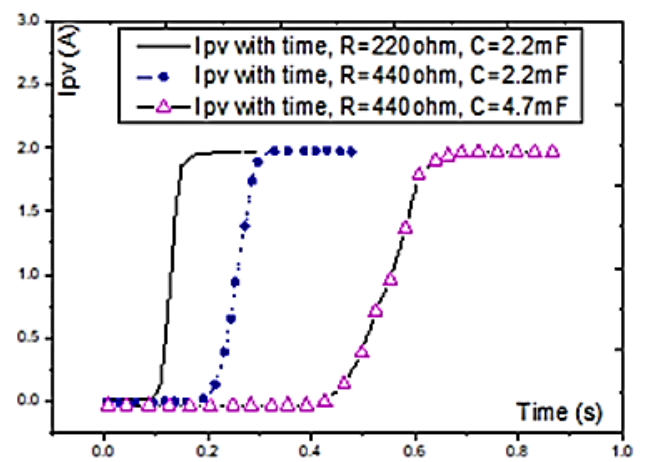

(a)

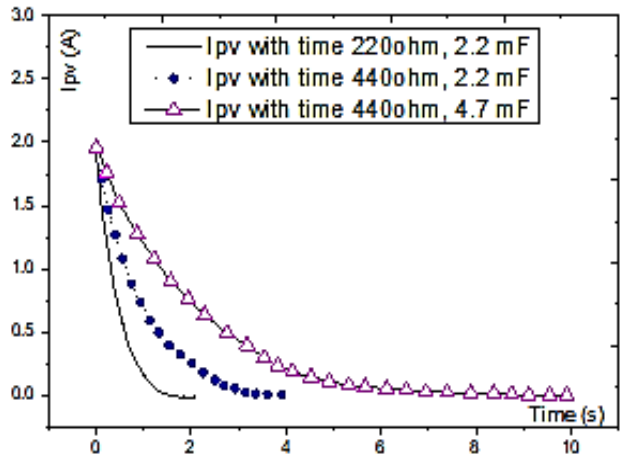

(b)

Figure 5. Ipv with time at different values of R and C; (a) with electronic load, (b) with capacitive load

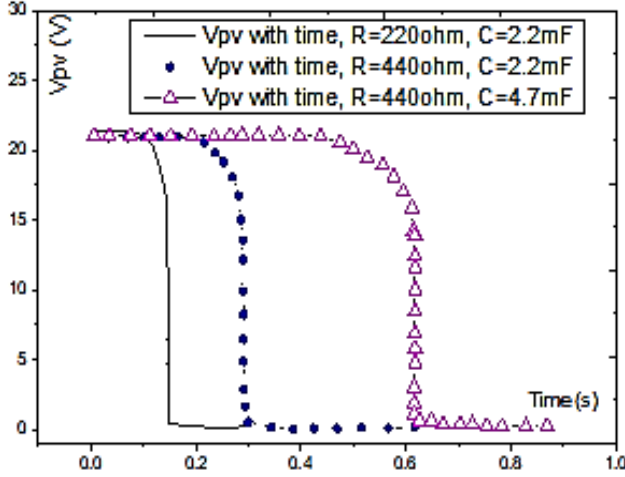

(a)

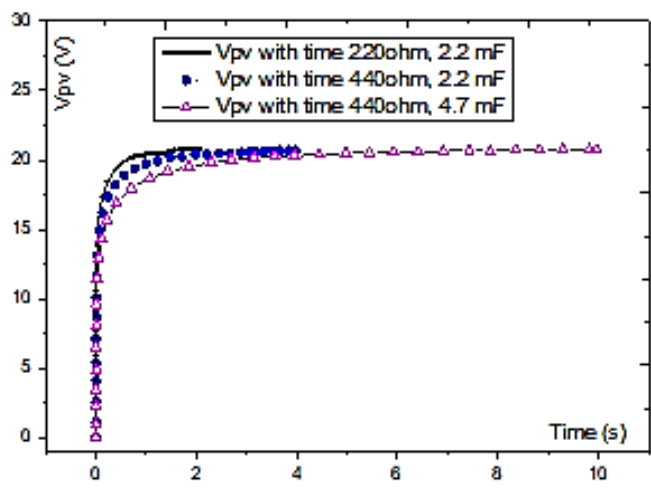

(b)

Figure 6. $V p v$ with time at different values of $\mathrm{R}$ and $\mathrm{C}$; (a) with electronic load, (b) with capacitive load 


\section{2. $I-V$ and $P-V$ characteristic of the $P V$ module}

The Figures 7 and 8 shows the $I-V \& P-V$ characteristics for the SX330J and ET-M53630 solar panels, Figures 7(a) and 8(a) using electronic technic, Figures 7(b) and 8(b) using capacitive load technic (MOSFET). A comparison between manufacturer's datasheet and the experimental data was performed under the weather conditions $\mathrm{G}=1000 \mathrm{~W} / \mathrm{m}^{2}, \mathrm{~T}=25^{\circ} \mathrm{C}$.

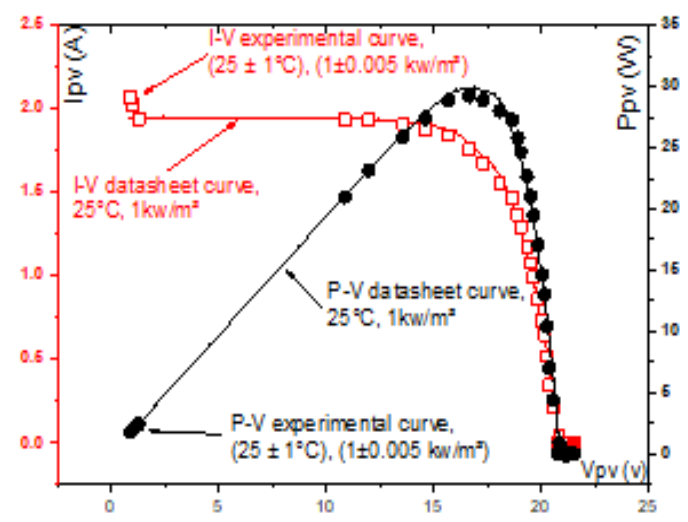

(a)

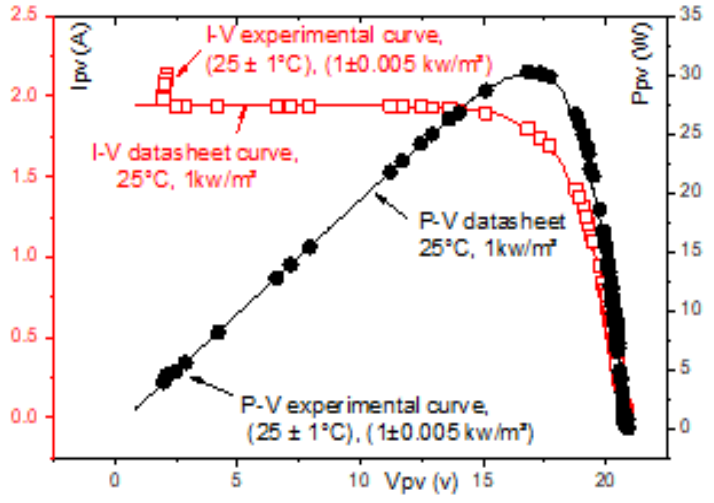

(b)

Figure 7. $I-V \& P-V$ characteristics of the SX 330J module; (a) with electronic load, (b) with capacitive load

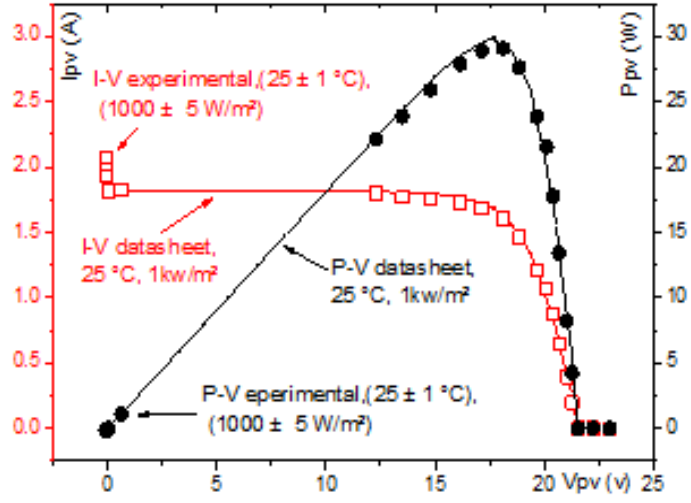

(a)

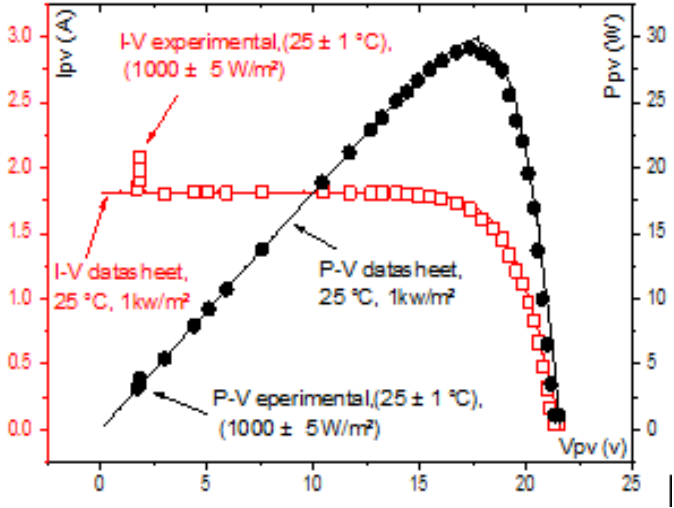

(b)

Figure 8. $I-V \& P-V$ characteristics of the ET-M53630 module; (a) with electronic load,

(b) with capacitive load

\subsection{Relative error between "capacitive" and "electronic" load technic:}

The relative errors Er between $I_{p v, \text { data }}$ given by the manufacturer, and the $I_{p v \text {,exp }}$ data measured by the "Capacitive" and "electronic" methods under the weather conditions $\mathrm{G}=1000 \mathrm{~W} / \mathrm{m}^{2}$ with Tcell $=25{ }^{\circ} \mathrm{C}$, is given in the following relation (19), this parameter evaluated for various values of the panel voltage Vpv by [22]-[25]:

$$
\operatorname{Er}(\%)=100\left(\frac{\left|I_{p v, e x p}-I_{p v, d a t a}\right|}{I_{p v, \exp }}\right)_{V_{p v}}
$$

From Figures 9 and 10 and the results of the comparison of the relative errors $\mathrm{Er}$ of $I-V$ characterization, we can conclude that the method using the MOSFET electronic charge is more accurate than the capacitive charge method, either based on a polycrystalline or monocrystalline panel, this results justifies the performance brought by the use of this "MOSFET" circuit method compared to the "Capacitive" circuit method, Table 3 summarizes all the positive points brought by the MOSFET method compared to the capacitive method. 

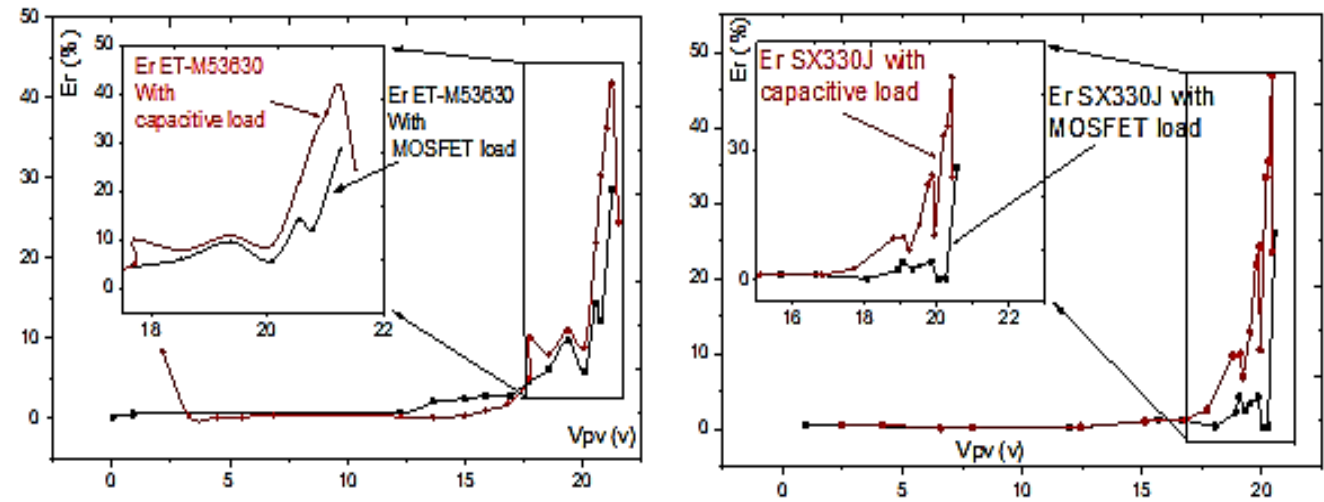

Figure 9. Relative errors Er, evaluating the "capacitive" and "electronic load" circuit methods
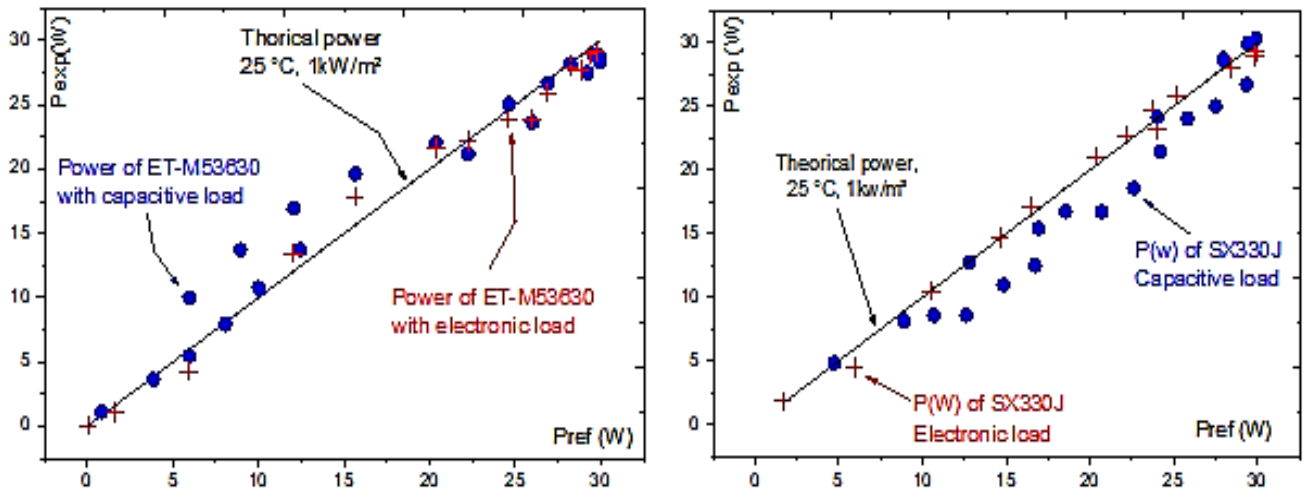

Figure 10. Experimental power, evaluating the "capacitive" and "electronic load" circuit methods

Table 3. Comparison between different methods

\begin{tabular}{ccccc}
\hline & Flexibility & Fidelity & time Response & Cost_ \\
\hline Capacitive load & Low & Medium & high & low \\
Electronic load & High & Medium & low & Medium \\
\hline
\end{tabular}

\subsection{Combining circuit between "capacitive" and "electronic" load technic}

In this part, we have tested the combination between the capacitive method and electronic charging to plot the $I-V$ and $P-V$ characteristics of a solar panel. The basic circuit of this combination is illustrated in Figure 11. A capacitor of capacitance $\mathrm{C}=4.7 \mathrm{mF}$ is added to the terminals of the MOSFET transistor. The control signal is similarly produced by Arduino, amplified by DC-DC booster, and then injected into an RC filter $(\mathrm{R}=440 \Omega, \mathrm{C}=4.7 \mathrm{mF})$, to vary the $\mathrm{V}_{\mathrm{GS}}$ voltage in a progressive way.

\subsubsection{Combining effect between "capacitive" and "electronic" load technic on Ipv and Vpv}

As shown Figure 12 the effect of the combination between capacitor and the MOSFET on the Figure 12(a) $I p v=f(t)$ and Figure 12(b) $V p v=f(t)$ characteristics, in the case of $\mathrm{R}=440 \mathrm{ohm}, \mathrm{C}=4.7 \mathrm{mF}$ and $\mathrm{R}=220 \mathrm{ohm}, \mathrm{C}=2.2 \mathrm{mF}$. From Figure $12 \mathrm{we}$ observe that the variations $I p v=f(t)$ and $V p v=f(t)$ have two effects: capacitive and electronic effect of the MOSFET, which consequently increases the number of points displayed by the PLX-DAQ and also decreases the plotting time of the Ipv-Vpv characteristics, i.e. $\operatorname{trp}=0.5 \mathrm{~s}$ for $(\mathrm{R}=440 \Omega, \mathrm{C}=4.7 \mathrm{mF})$, thus $0.1 \mathrm{~s}$ less than the method which uses only the MOSFET without combination as shown in Figures 5 and 6.

\subsection{2. $I-V$ and $P-V$ characteristic with the combined circuit "capacitive" and "electronic" load}

In the Figures 13 and 14 benchmarking study between combination capacitive-electronic load and electronic load has been performed, Figure 13(a) and 14(a) show electronic load technic, and Figure 13(b) and 14(b) with the combined circuit under STC. From Figures 13 and 14 we can see an agreement between the datasheet and the combination results between capacitive and electronic load. Moreover, we have noted that this combination increases the number of points, in Figures 13(b) and 14(b). The relative errors $\operatorname{Er}(\%)$ 
evaluated are shown in Figure 15. Figure 15(a) for ET-M53630 monocrystalline solar panel, and Figure 15(b) for SX330J polycrystalline solar panel. As shown in Figure 15, we can conclude that the combined circuit has a lower relative error Er compared to the previous technic. This justifies the performances brought by this combination compared to the capacitive or electronic load method.

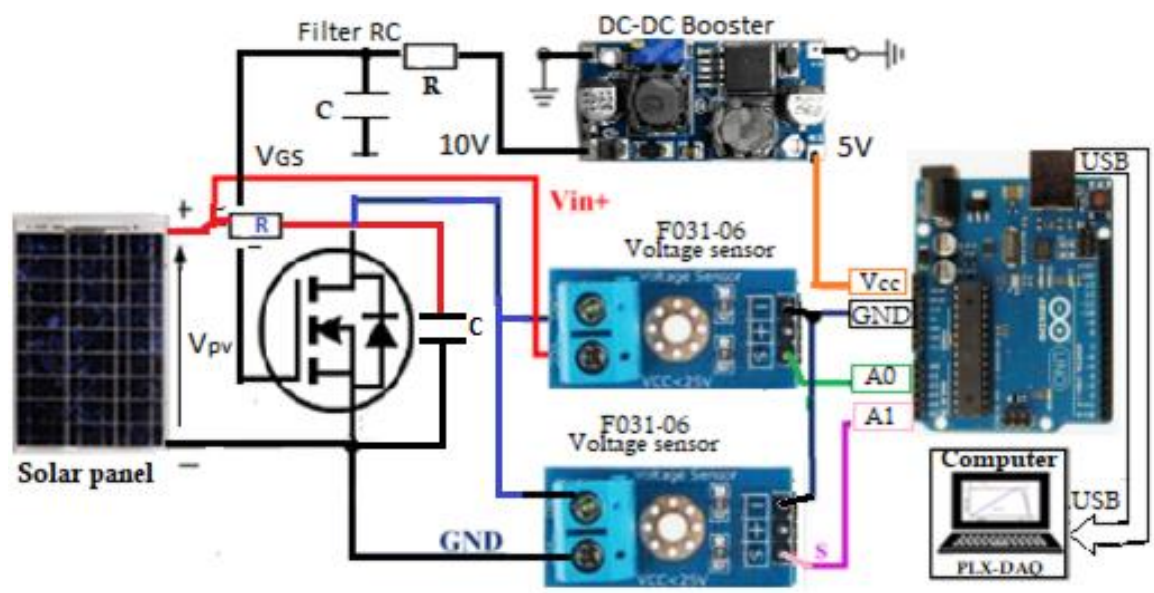

Figure 11. Combining between the "capacitive" and "electronic load" circuit

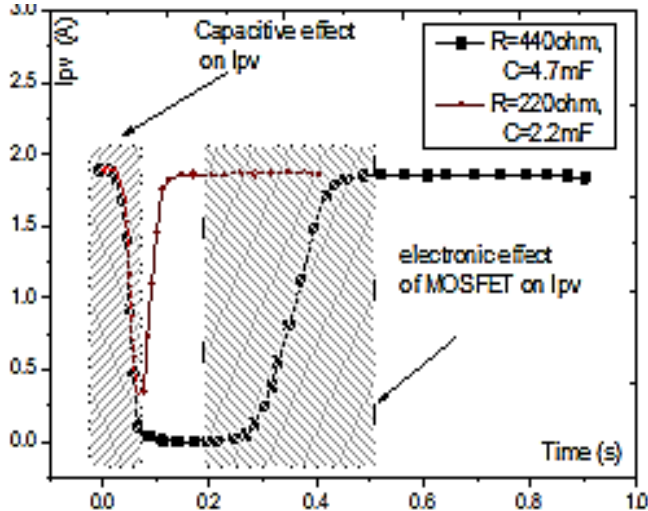

(a)

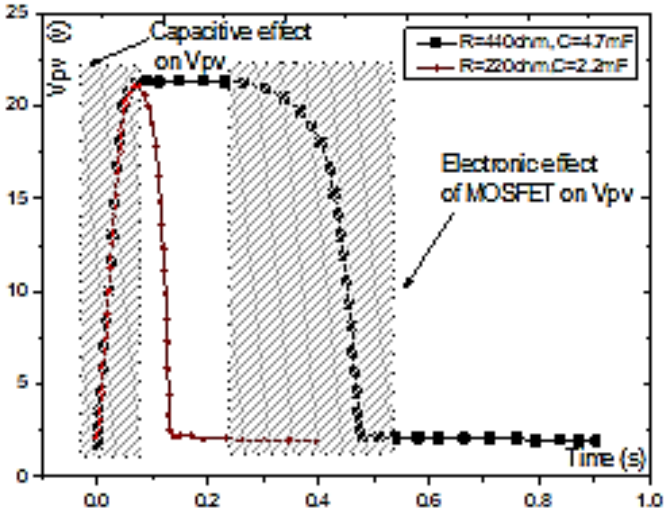

(b)

Figure 12. $V p v$ and $I p v$ with time at different values of the filter $\mathrm{R}$ and $\mathrm{C}$; (a) $I p v=\mathrm{f}(\mathrm{t}),(\mathrm{b}) V p v=\mathrm{f}(\mathrm{t})$

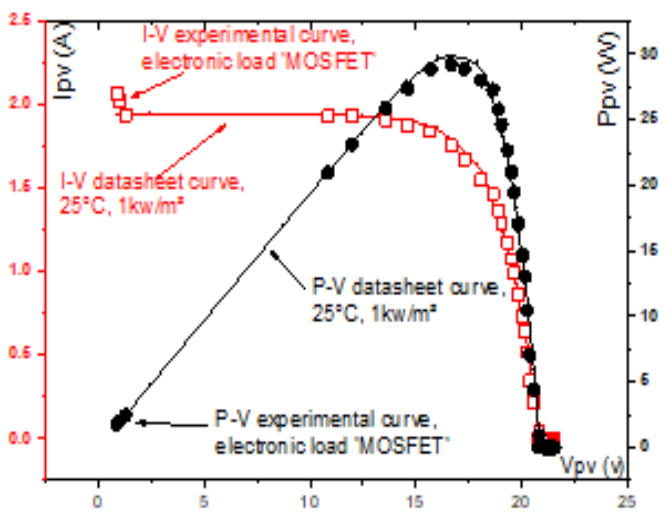

(a)

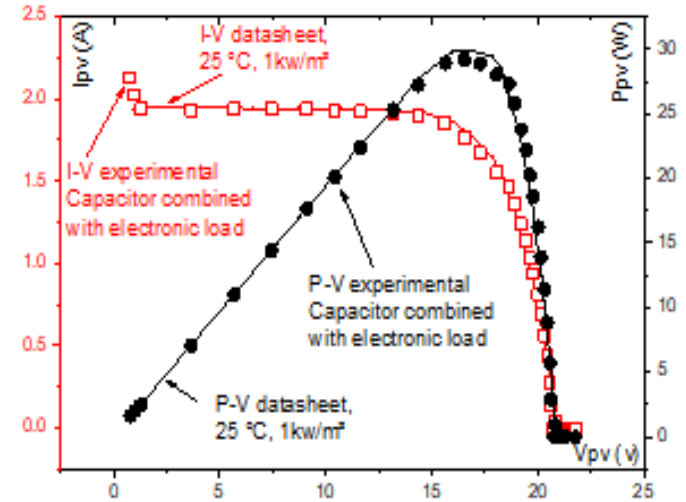

(b)

Figure 13. $I-V \& P-V$ characteristics of the SX330J module; (a) with electronic load, (b) electronic load combined with capacitive load 


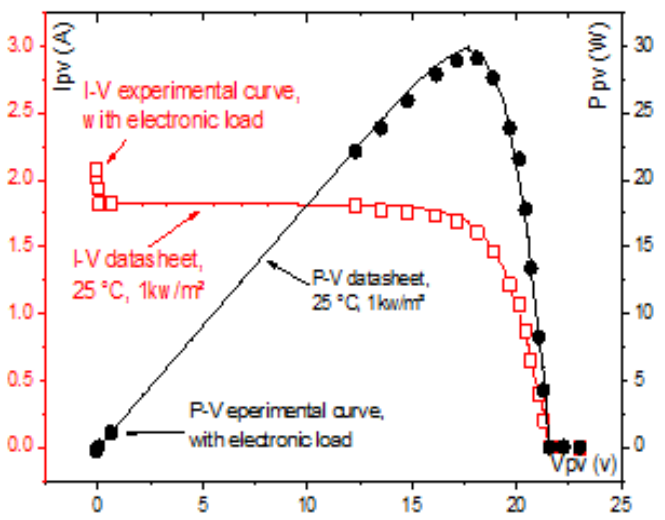

(a)

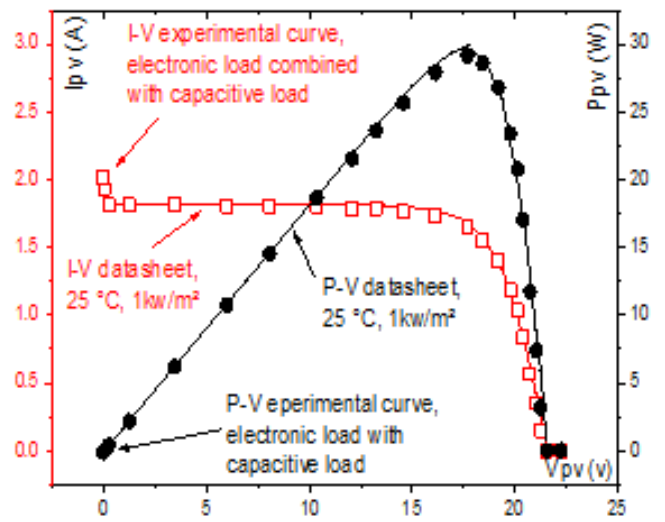

(b)

Figure 14. $I-V \& P-V$ characteristics of the ET-M53630 module; (a) with electronic load, (b) electronic load combined with capacitive load

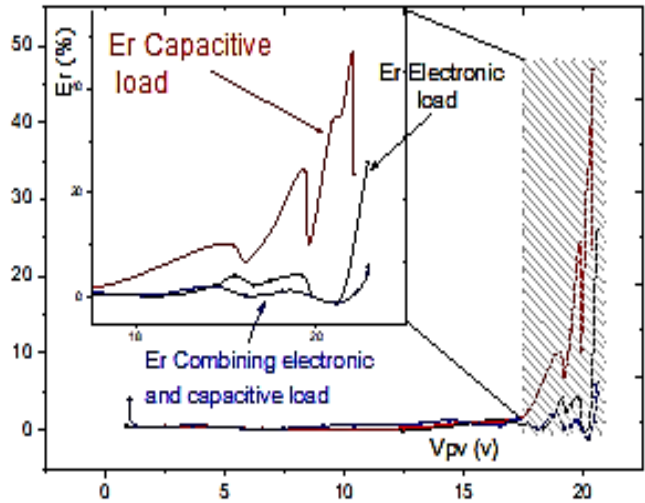

(a)

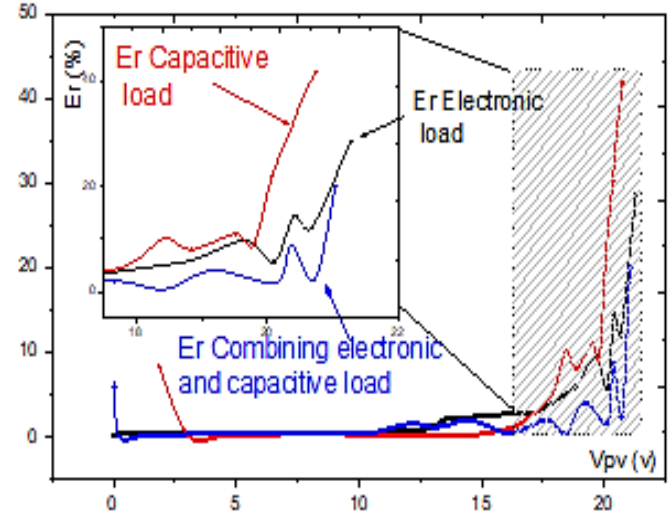

(b)

Figure 15. Relative errors Er evaluating electronic load combined with capacitive load:

(a) ET-M53630 module, (b) SX330J module

\section{CONCLUSION}

In this paper, two low-cost solutions to provide the $I-V \& P-V$ characteristics of the solar panel have been proposed. As an improvement, a combination of these two techniques was carried out. The whole system is based on simple components, and especially widely used in laboratories, based on a simple circuit with electronic load "MOSFET", or capacitive load. The acquisition is done through low-cost voltage sensors in communication with an Arduino board, and the data is presented in real-time using the PLX-DAQ Spreadsheet data interface in Excel Macro. The experimental results are in agreement with the theoretical analysis. An improvement has been observed in terms of accuracy, response time, and cost of the instrumentation used. Experimental tests on a PV module of the type monocrystalline ET-M53630 or polycrystalline SX 330J have been carried out under real operating conditions. The proposed circuit is suitable for use in detecting solar panel defects and understanding the effect of external parameters such as fluctuations in illumination, temperature, and the effect of a type of dust on a PV system.

\section{REFERENCES}

[1] Y. Chaibi, M. Malvoni, A. Chouder, M. Boussetta, and M. Salhi, "Simple and efficient approach to detect and diagnose electrical faults and partial shading in photovoltaic systems," Energy Conversion and Management, vol. 196, pp. 330-343, 2019, doi: 10.1016/j.enconman.2019.05.086.

[2] Q. Alsafasfeh, "An efficient algorithm for power prediction in PV generation system," International Journal of Renewable Energy Development, vol. 9, no. 2, pp. 207-216, 2020, doi: 10.14710/ijred.9.2.207-216.

[3] M. Rasheed, S. Shihab, and T. Rashid, "Two step and newton-raphson algorithms in the extraction for the parameters of solar cell,” Al-Qadisiyah Journal of Pure Science, vol. 26, no. 1, pp. 143-154, 2021, doi: 10.29350/qjps.2021.26.1.1260. 
[4] Y. Zhu and W. Xiao, “A comprehensive review of topologies for photovoltaic I-V curve tracer," Solar Energy, vol. 196, pp. 346-357, 2020, doi: 10.1016/j.solener.2019.12.020.

[5] S. Sarikh, M. Raoufi, A. Bennouna, A. Benlarabi, and B. Ikken, "Implementation of a plug and play I-V curve tracer dedicated to characterization and diagnosis of PV modules under real operating conditions," Energy Conversion and Management, vol. 209, 2020, doi: 10.1016/j.enconman.2020.112613.

[6] S. Yadir et al., "Evolution of the physical parameters of photovoltaic generators as a function of temperature and irradiance: New method of prediction based on the manufacturer's datasheet," Energy Conversion and Management, vol. 203, 2020, doi: 10.1016/j.enconman.2019.112141.

[7] F. Spertino, J. Ahmad, A. Ciocia, P. Di Leo, A. F. Murtaza, and M. Chiaberge, "Capacitor charging method for I-V curve tracer and MPPT in photovoltaic systems," Sol. Energy, vol. 119, pp. 461-473, 2015, doi: 10.1016/j.solener.2015.06.032.

[8] D. T. Cotfas, P. A. Cotfas, D. Ursutiu, and C. Samoila, "Current-voltage characteristic raising techniques for solar cells. comparisons and applications," 12th International Conference on Optimization of Electrical and Electronic Equipment, Romania, 2010, pp. 1115-1120, doi: 10.1109/OPTIM.2010.5510373.

[9] Z. Chen, W. Lin, L. Wu, C. Long, P. Lin, and S. Cheng, "A capacitor based fast I-V characteristics tester for photovoltaic arrays," Energy Procedia, vol. 145, pp. 381-387, 2018. doi: 10.1016/j.egypro.2018.04.032.

[10] Z. Chen, Y. Lin, L. Wu, S. Cheng, and P. Lin, "Development of a capacitor charging based quick I-V curve tracer with automatic parameter extraction for photovoltaic arrays," Energy Conversion and Management, vol. 226, 2020, doi: 10.1016/j.enconman.2020.113521.

[11] C. Li, Y. Yang, S. Spataru, K. Zhang, and H. Wei, "A robust parametrization method of photovoltaic modules for enhancing onediode model accuracy under varying operating conditions," Renewable Energy, vol. 168, pp. 764-778, 2021, doi: 10.1016/j.renene.2020.12.097.

[12] O. W. Yin and B. C. Babu, "Simple and easy approach for mathematical analysis of photovoltaic (PV) module under normal and partial shading conditions," Optik, vol. 169, pp. 48-61, 2018, doi: 10.1016/j.ijleo.2018.05.037.

[13] A. Hemza, H. Abdeslam, C. Rachid, and N. Aoun, "Simplified methods for evaluating the degradation of photovoltaic module and modeling considering partial shading," Measurement, vol. 138, pp. 217-224, 2019, doi: 10.1016/j.measurement.2019.01.098.

[14] M. Piliougine, G. Spagnuolo, and M. S. de-Cardona, "Series resistance temperature sensitivity in degraded mono-crystalline silicon modules," Renewable Energy, vol. 162, pp. 677-684, 2020, doi: 10.1016/j.renene.2020.08.026.

[15] A. Tihane, M. Boulaid, L. Boughamrane, M. Nya, and A. Ihlal, "experimental analysis and modeling of performances of silicon photovoltaic modules under the climatic conditions of Agadir," IOSR Journal of Electrical and Electronics Engineering, vol. 12, no. 5, pp. 42-46, 2017, doi: 10.9790/1676-1205014246.

[16] D. Nichols, "Arduino-based data acquisition into Excel, LabVIEW, and MATLAB," The Physics Teacher, vol. 55, no. 4, pp. 226227, 2017, doi: 10.1119/1.4978720.

[17] "Datasheet Solarimètre FI 109SM," Distrame, 2020. [Online]. Available: https://www.distrame.fr/fr/website/Resultat-derecherche-avec-InstantSearch,839332.html? q=FI+109SM\&submit=

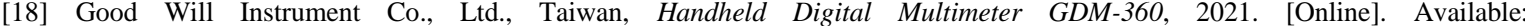
https://www.gwinstek.com/en-global/products/downloadSeriesDownNew/9890/718

[19] S. Sarikh, M. Raoufi, A. Bennouna, A. Benlarabi, and B. Ikken, "Design of an I-V characteristic tracer for photovoltaic systems," International Renewable and Sustainable Energy Conference (IRSEC), Tanger Morocco, Dec. 2017, doi: 10.1109/IRSEC.2017.8477298.

[20] A. Asbayou, M. Agdam, A. Aamoume, A. Soussi, A. Ihlal, and L. Bouhouch, "Utilization of MOSFET transistor as an electronic load to trace I-V and P-V curve of a solar panel," The $3^{\text {rd }}$ International Conference of Computer Science and Renewable Energies (ICCSRE'2020), Agadir, Morocco, 2021, pp. 1-8, doi: 10.1051/e3sconf/202122901021.

[21] A. A. Willoughby and M. O. Osinowo, "Development of an electronic load I-V curve tracer to investigate the impact of Harmattan aerosol loading on PV module pern2tkformance in southwest Nigeria," Solar Energy, vol. 166, pp. 171-180, 2018, doi: 10.1016/j.solener.2018.03.047.

[22] M. Louzazni, A. Khouya, K. Amechnoue, M. Mussetta, and A. Crăciunescu, "Comparison and evaluation of statistical criteria in solar cell and photovoltaic module parameters extraction,” International Journal of Ambient Energy, vol. 41, no. 13, pp. 14821494, 2018, doi: 10.1080/01430750.2018.1517678.

[23] M. F. Al-Hajri, K. M. El-Naggar, M. R. Al-Rashidi, and A. K. Al-Othman, "Optimal extraction of solar cell parameters using pattern search,” Renewable Energy, vol. 44, pp. 238-245, 2012, doi: 10.1016/j.renene.2012.01.082.

[24] A. Chouder, S. Silvestre, N. Sadaoui, and L. Rahmani, "Modeling and simulation of a grid connected PV system based on the evaluation of main PV module parameters," Simulation Modelling Practice and Theory, vol. 20, no. 1, pp. 46-58, 2012, doi: 10.1016/j.simpat.2011.08.011.

[25] A. Askarzadeh and A. Rezazadeh, "Artificial bee swarm optimization algorithm for parameters identification of solar cell models," Applied Energy, vol. 102, pp. 943-949. 2013. doi:10.1016/j.apenergy.2012.09.052.

\section{BIOGRAPHIES OF AUTHORS}

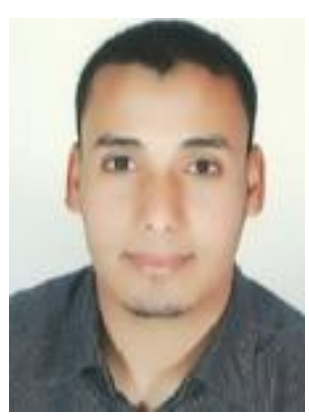

Abdellah Asbayou (D) 8. SC P was born in Agadir, Morocco, in 1988. Supply teacher of Electrical Engineering at the High School of Technologies in Agadir (ESTA). His research in the context of national doctoral thesis focuses on the thematic of Renewable Energy. He can be contacted at email: abdellah.asbayou@edu.uiz.ac.ma 

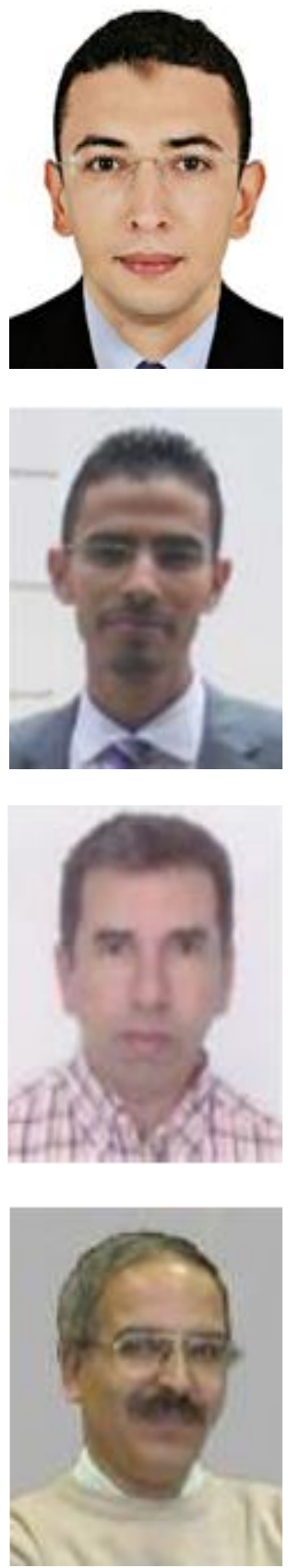

Amine Aamoume (iD 88 SC P was born in Agadir, Morocco, His research in the context of national doctoral thesis focuses on the thematic of Renewable Energies. He can be contacted at email: aamoume@gmail.com

Mustapha Elyaqouti (iD SC SC Pas born in Morocco. His research focuses on the thematic of Renewable Energies. He can be contacted at email: elyaqouti@mail.com
Ahmed Ihlal (D) 81 SC P Professor of higher education at the FSA (faculty of science Agadir), president of. Laboratory of Materials and Renewable Energies, University Ibn Zohr, Agadir, Morocco. His research focuses on topics related to renewable energy. He can be contacted at email: a.ihlal@uiz.ac.ma

Lahoussine Bouhouch (D) SC P Professor of higher education at the ESTA (High School of Technologies of Agadir), Ibn Zohr University, Agadir - Morocco. His research focuses on topics related to renewable energy, instrumentation, electromagnetic compatibility (EMC) and Embedded systems. He can be contacted at email: 1.bouhouch@uiz.ac.ma 